\title{
Balance, gait and quality of life in Parkinson's disease: Effects of whole body vibration treatment
}

\section{Equilíbrio, marcha e qualidade de vida na Doença de Parkinson: efeitos de um tratamento de vibração de corpo inteiro}

\author{
Ludmylla Teixeira Soares $^{[\mathrm{a}]}$, Aldo José Fontes Pereira ${ }^{[\mathrm{b}]}$, Lílian Danielle Paiva Magno ${ }^{[\mathrm{c}]}$, \\ Hugo de Melo Figueiras ${ }^{[\mathrm{d}]}$, Luciane Lobato Sobral ${ }^{[\mathrm{e}]}$ \\ [a] Spec., Universidade do Estado do Pará, Centro de Ciências Biológicas e da Saúde, Belém, PA - Brazil, e-mail: \\ ludmyllasoares.pt@gmail.com \\ [b] PhD candidate, researcher, Universidade do Estado do Pará, Belém, PA - Brazil, e-mail: aldo.fontes@gmail.com \\ [c] MSc, Universidade Federal do Pará, Programa de Pós-Graduação em Neurociências e Biologia Celular, Belém, PA - Brazil, \\ e-mail: magno.lilian@yahoo.com.br \\ [d] MSc candidate, physiotherapist, Hospital Ophir Loyola, Belém, PA - Brazil, e-mail: hugobelem@hotmail.com \\ [e] MSc, professor, Universidade do Estado do Pará, Departamento de Ciências do Movimento Humano, Belém, PA - Brazil, \\ e-mail: lucianelobatosobral@gmail.com
}

\begin{abstract}
Introduction: Parkinson's disease (PD) is a neurodegenerative disorder, which triggers limitations and disability in people. Therefore, rehabilitation therapy is widely recommended in patients with PD, especially those who do not respond to pharmacological treatment. Objective: Evaluate the effect of a protocol of Whole-body Vibration (WBV) in balance, gait and Quality of Life (QOL) of patients with PD, who do not respond to pharmacological treatment. Methods: It was performed 12 sessions of a protocol WBV (squat, plantar flexion, isometric contraction of members and single-leg balance), with three sets each, at a vibrating platform $(2 \mathrm{~mm}$ and $35 \mathrm{~Hz})$ in 10 PD patients. By the first 3 sessions, patients underwent 20 seconds of exercise and 20 seconds of rest. After the third session, the treatment was 40 seconds of exercise and 20 seconds of rest. The Tinetti Test was applied before and after treatment to assess balance and gait, and the Parkinson's Disease Quality of Life-questionnaire (PDQL-BR), to evaluate the PDQL-BR and its subcategories: Parkinson, Systemic, Social and Emotional. Results: Treatment did not significantly change the balance $(p=0.438), Q O L$ issue in Emotional $(p=0.450)$ and Social $(p=0.171)$, but improved gait $(p=0.003)$, the
\end{abstract}


Tinetti ( $p \leq 0.001)$, the quality of life in items Parkinson ( $p \leq 0.001)$, Systemic $(p \leq 0.001)$ and PDQL-BR ( $p \leq 0.001$ ). Conclusions: WBV exercises on the vibrating platform, according to the parameters used, showed promising results that encourage its use to improve the clinical conditions related to disorders of gait, balance and QOL in patients with PD.

Keywords: Parkinson disease. Clinical protocols. Physiotherapy. Quality of life. Vibration.

\section{Resumo}

Introdução: A Doença de Parkinson (DP) é uma desordem neurodegenerativa que desencadeia limitações e incapacidades nos indivíduos. Assim, a terapia de reabilitação é amplamente recomendada em parkinsonianos, principalmente aos que não respondem ao tratamento farmacológico. Objetivo: Avaliar os efeitos de um protocolo de Vibração de Corpo Inteiro (VCI) no equilíbrio, na marcha e na Qualidade de Vida (QV) de pacientes com DP, que não respondiam ao tratamento farmacológico. Métodos: Realizou-se 12 sessões de um protocolo de VCI (agachamento, flexão plantar, contração isométrica de membros e equilíbrio unipodal), com 3 séries cada, na plataforma vibratória ( $2 \mathrm{~mm}$ de amplitude e $35 \mathrm{~Hz}$ ) em 10 parkinsonianos. Nas três primeiras sessões, os pacientes realizaram 20s de exercícios e 20s de repouso. Após a terceira sessão, o tratamento foi de 40 s de exercícios e 20s de repouso. Foi aplicado, antes e após o tratamento, o Teste de Tinetti, para avaliar equilíbrio e marcha, e o questionário sobre QV, Parkinson Disease Quality of Life (PDQL-BR), para avaliar o PDQL-BR e as suas subcategorias: Parkinson, Sistêmico, Emocional e Social. Resultados: $O$ tratamento não alterou significativamente o equilíbrio ( $p=0,438)$, a QV na questão Emocional $(p=0,450)$ e Social $(p=0,171)$, porém melhorou a marcha ( $p=0,003)$, o Tinetti Total ( $p \leq 0,001)$, a qualidade de vida nos itens, Parkinson ( $p \leq 0,001)$, Sistêmico $(p \leq 0,001)$ e PDQL-BR $(p \leq 0,001)$. Conclusão: Os exercícios de VCI na plataforma vibratória, segundo os parâmetros utilizados, apresentaram resultados promissores que incentivam o seu uso para melhorar as condições clínicas, referentes aos distúrbios da marcha, equilíbrio e QV em pacientes com DP.

Palavras-chave: Doença de Parkinson. Protocolos clínicos. Fisioterapia. Qualidade de vida. Vibração.

\section{Introduction}

Parkinson's disease (PD) is a chronic progressive neurodegenerative disorder of the nervous system (1, $2)$, and mainly characterized by tremor, rigidity (1, $3)$, bradykinesia (1,3), hypokinesia, akinesia (3) and postural abnormalities $(1,2)$, which trigger several limitations and disability in affected individuals. In addition, the PD patient may have cognitive disorders $(3,4)$, complications in speech and swallowing $(2,3)$, struggle for participating in social life (2) and even depression $(5,6)$. Therefore, all these signs and symptoms interfere negatively on quality of life (QOL) of those $(5,7,8)$.

Postural instability and gait impairment are major determinants of disability in PD, from the responses often unsatisfactory to dopaminergic treatment (9). Thus, for those who do not respond to pharmacological treatment $(3,9)$ rehabilitation therapy is widely recommended.
The Whole-body vibration (WBV) is a method in which the patient performs, safely and efficiently, exercises on a vibrating platform regarding the limitations of the patient. Thus, this modality fits into the ideal PD physical therapy model, well pointed out by Morris (3), once the exercises can be performed statically, sitting, leaning and dynamic (10). In the last decade, there is growing interest from neuroscientists and therapists when using WBV (11) as a new therapeutic modality that improves neuromuscular performance $(9,10,11)$.

Ebersbach et al. (9) compared the effects of WBV (4 weeks protocol - two sessions of 15 minutes/day in 5 days/week) with the conventional therapy in $21 \mathrm{PD}$ patients (10 were treated WBV and 11 were treated with conventional physiotherapy) and concluded that there was no difference between the two treatments. Additional studies suggest that WBV has increased muscle strength (12), the posture control (13) and quality of life (14). 
Tinetti Test or Performance Oriented Mobility Assessment - POMA (15) has been named in most studies as a reliable instrument for assessing changes in balance and gait abnormalities in PD (16). However, Parkinson's Disease Quality of Lifequestionnaire (PDQL-BR) can measure the impact of PD on QOL (17). It is worth noting that there are few studies that address the effects of WBV on these patients QOL $(18,19)$ and, to this research, no studies were found, that have quantified the relationship of balance and gait in QOL in individuals with PD, who did not respond to drug treatment, treated by WBV.

Consequently, this study aims to elucidate the effects of a simple WBV protocol in PD patients who do not respond to drug treatment, assessing the balance, gait and QOL.

\section{Methods}

\section{Ethical features}

The study was conducted according to the principles of the Declaration of Helsinki of the Nuremberg Code (1947), respecting the norms of human research of the National Health Council (CNS 196/96), and approved by the Ethics Committee in Research of the University of Pará (UEPA) (Protocol N. 28/2011).

\section{Samples}

The series consisted of 10 PD volunteers, Brazilians, not amputated, between stages 1-3 of the Hoehn \& Yahr scale (HY), (20) score between 19-30 points for literate or 19-28 points for illiterates in cognitive assessment by the Mini Mental State Examination (MMSE) (21), who did not respond to pharmacological treatment and waiting the beginning of conventional treatment in the physiotherapy sector UEAFTO (Physical Therapy and Occupational Therapy Ambulatory Teaching Unit). The research was conducted at the Clinic Figueiras Reabilitação, the morning shift, during the period July-August 2011. Traumatology rehabilitation is the specialty of the clinic, located in Travessa 9 de Janeiro, 1566 São Braz - Belém - PA.

\section{Experimental setup}

The implementation of the study occurred in three steps:

i) It was carried out analyzing the charts of all patients with a clinical diagnosis of PD who were not in attendance at UEAFTO $(n=23)$, in order to verify the presence of exclusion criteria of the study, i.e., patients stage 4 and 5 of the disease according to HY, patients with systemic commitments, complete disability, wheelchair users, people with pacemakers, kidney disease, gallstones, thrombosis (the last six months), acute lumbago, unconsolidated fracture, joint prosthesis (for less than 12 months), lower limb amputations (excluding fingers), Raynaud's disease and cognitive decline (less than 19 points on the MMSE score). Following examination, the patients in course were contacted and informed about the goals and procedures of evaluation and treatment. Individuals who agreed to participate signed an informed consent form (ICF), accomplishing the sample size used in the study $(n=10)$. The data of the volunteers were organized and stored in envelopes with their initial registration. Subsequently, followed an individual assessment using the instruments below:

- Hoehn \& Yahr scale;

- MMSE;

- Tinetti Test;

- PDQL-BR;

The assessments were conducted in a reserved place, with suitable size $\left(18 \mathrm{~m}^{2}\right)$, respectable lighting, exterior noise and interruptions free and individuality (except when patients commandeer the presence of the companion).

For the assessment of balance and gait, Tinetti Test was used. In this test, the patient starts sitting on a hard, rigid and armrestless chair. Points are awarded according to the parameters presented by examined, corresponding to balance, indicated as Tinetti Balance (TB): sitting balance; to lift; attempt to lift; the first 5 seconds behaviors after lift; standing balance; test in three fields (the examiner gently pushes the sternum of the individual); eyes closed; turning $360^{\circ}$ and sitting. 
The same principles were applied for gait analysis, indicated as Tinetti Gait (TG): the patient is standing, wanders down the hall or across the room and back to a normal pace with rapid steps, but using the usual support. The score is the observation of the following parameters: start of the gait; length and height of the steps; symmetry of the steps; continuity of steps; direction; trunk; distance ankles.

As for the assessment of QOL in PD, was held through the PDQL-BR-questionnaire. The volunteers answered 37 questions about issues related to factors of PD (systemic, social and emotional). Responses were scored according to the frequency: (1) all the time; (2) usually; (3) a few times; (4) rarely; (5) never. The results were documented to a posterior judgment after 12 treatment sessions.

ii) The protocol was established according to the parameters of short-time exercises (22) with 12 sessions on the vibration platform Globus ${ }^{\circledR}$ (Globus Italia Srl., Codognè, ITA), $2 \mathrm{~mm}$ amplitude and $35 \mathrm{~Hz}$. Followed the following treatment protocol:

- There were four exercises (squats, plantar flexion, isometric contraction of members and single-leg balance) three sets each (Figure 1);

- In the first three sessions, patients underwent 3 sets of 20 s and 20 s exercise of rest in order to adapt them to exercise (Figure 2A);

- After the third session, the treatment was 40s of exercise and 20s of rest (Figure 2B).

iii) After 12 sessions, Tinetti Test was taken again and reapplied to PDQL-BR.

\section{Statistical method}

By using Microsoft Excel ${ }^{\circledR} 2010$ spreadsheet, data were compiled in order to obtain the averages and age standard deviations from the participants. Tests of normality and equal variance were used to make sure that the paired Tinetti test had met the criteria for use in this analysis. When one of the criteria was not met, the nonparametric Wilcoxon test was performed. The variables analyzed before and after treatment were: TB, TG, Tinetti Total, Total PDQL-BR and subcategories of PDQL-BR (Parkinson, systemic, emotional and social).
In order to check if the sex factor influenced the variables mentioned above, we used the two-way ANOVA for repeated measures. Furthermore, we analyzed the Pearson Correlation Coefficient between the score of the Tinetti Test and QOL. Statistical procedures were performed in SigmaStat 3.5 statistical software (Systat Software, Inc., San Jose, CA, USA). The level of significance of $\alpha=0.05$ was adopted.

\section{Results}

Data collected before and after the exercise intervention with the platform in 10 volunteers, have provided information on the WBV effects in this population.

The distribution of gender was characterized by equivalent frequency of 50\% male and 50\% female. The average age of the volunteers group was $61.70 \pm$ 9.57 years, $59.40 \pm 11.87$ years for males and $64.00 \pm$ 7.21 years for females. As for the HY scale, the group was characterized by $40 \%$ in stage $1,50 \%$ in stage 2 and $10 \%$ in stage 3 , and $60 \%$ females were in stage 1 and $80 \%$ male in stage 2 . After training, only the so-called patient 8 changed from stage 2 to 1 in HY.

WBV Treatment does not significantly alter the balance of the volunteers, examined by TB [W = 6.000; $\mathrm{p}=0.438]$, unlike the TG [t (9) = 3.973; $\mathrm{p}=$ 0.003 ] and Tinetti Total [ $\mathrm{t}(9)=-4.792 ; \mathrm{p} \leq 0.001$ ], which had higher scores after treatment with the vibrating platform (Figure 3). The sex does not influence the values of TB $[F(1.19)=0.094 ; p=0.762]$, TG $[\mathrm{F}(1.19)=0.618 ; \mathrm{p}=0.443]$ and Tinetti Total $[\mathrm{F}$ $(1.19)=0.092 ; p=0.765]$.

Investigating the subcategories of PDQL-BR, there was a significant increase in the subcategories Parkinson [t $(9)=-6.130 ; \mathrm{p} \leq 0.001]$ and Systemic $[\mathrm{t}$ (9) $=-5.518 ; p \leq 0.001]$, with no significant change in the subcategories Emotional [t $(9)=-0.789 ; \mathrm{p}=$ 0.450 ] and Social [t (9) $=-1.489 ; p=0.171$ ] (Figure $4 \mathrm{~A}$ ). The total result of PDQL-BR also showed an increase after treatment with WBV [t (9) = -6.580; $\mathrm{p} \leq$ 0.001] (Figure 4B).

There was no any interaction between sex and the values of the PDQL-BR subcategories before and after treatment, Parkinson $[\mathrm{F}(1.19)=0.203 ; \mathrm{p}=0.659]$, systemic $[F(1.19)=0.0612 ; p=0.808]$, emotional $[F$ $(1.19)=0.597 ; p=0.451]$, Social $[F(1)=0.00438 ; p=$ $0.948]$ and Total PDQL-BR [F (1) $=0.160 ; p=0.694]$. 

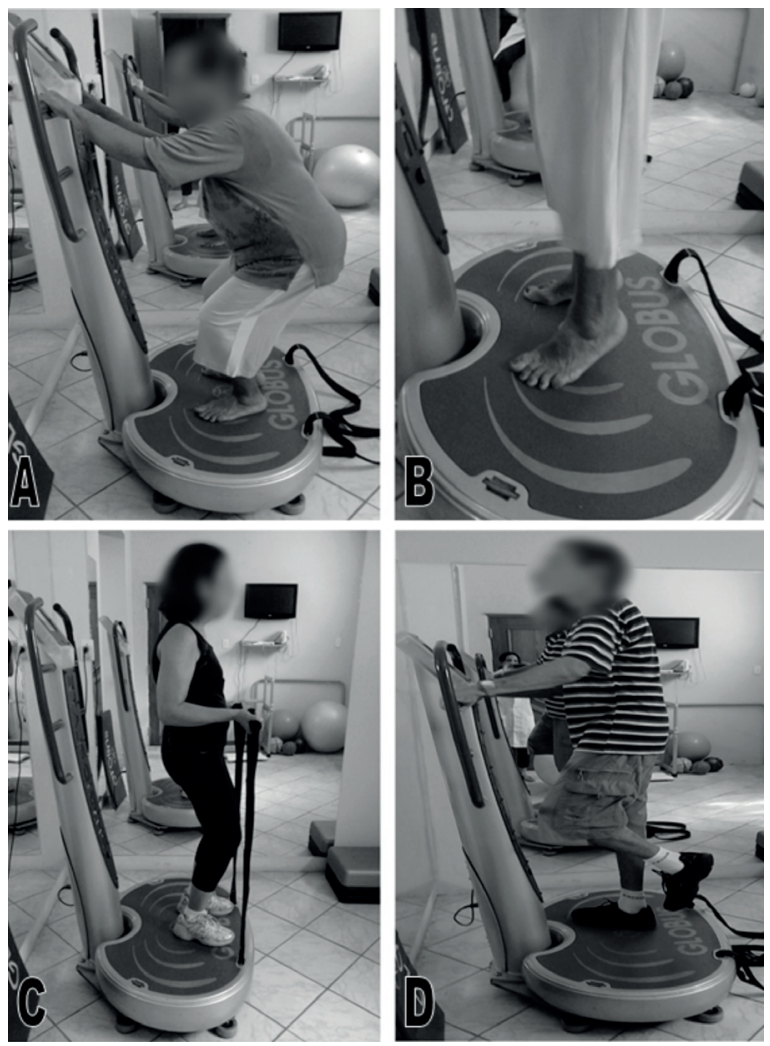

Figure 1 - Exercises held in vibration platform: A - Squat; B - plantar flexion; C - isometric contraction of members and D single-leg balance

Source: Research data.
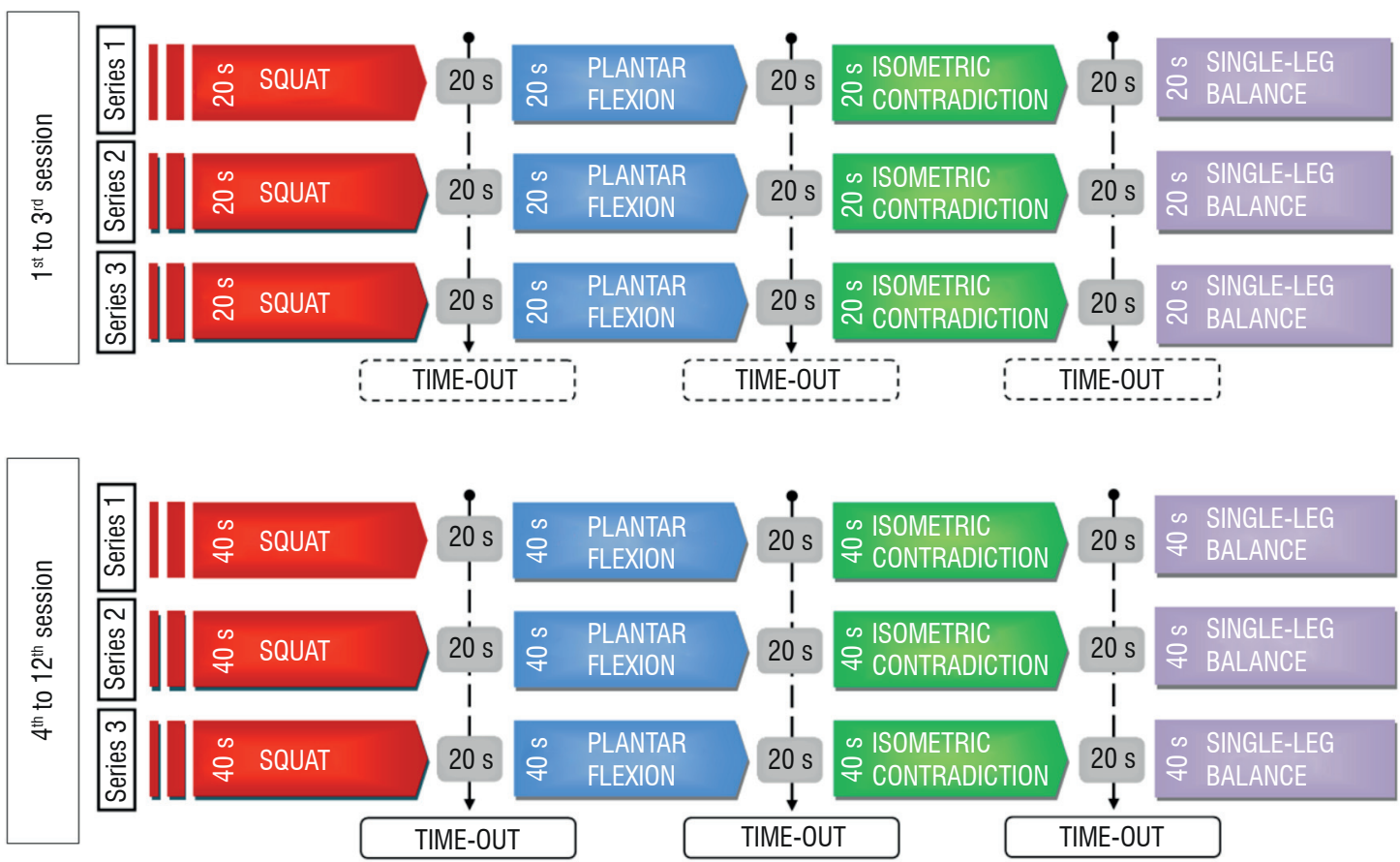

Figure 2 - Whole body vibration treatment protocol: A - Held the first three sessions; B - Held the last nine sessions Source: Research data. 
There was a positive correlation between the Tinetti Test and QOL both before ( $\mathrm{r}=0.699, \mathrm{p}=$ $0.024)$ and after $(r=0.729, p=0.016)$ of treatment (Figure 5).

\section{Discussion}

PD leads to changes in the balance/gait and QOL of PD patients. The Tinetti Test and PDQL-BR. can

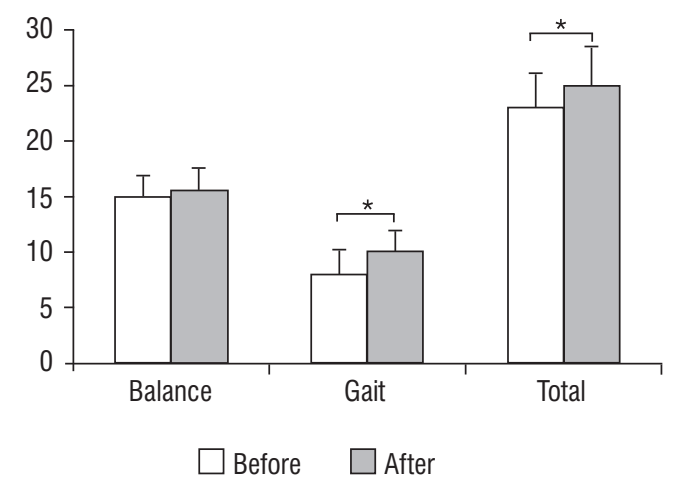

Figure 3 - Tinetti Balance, Tinetti Gait e Tinetti Total, before and after treatment

Note: ${ }^{*} p<0.05$.

Source: Research data. quantify these changes respectively. Thus, these tests may assist in research to develop tools that work on the improvement of individuals with Parkinson's disease. Currently, the WBV is a treatment modality that has been widely used for improvement in neuromuscular performance of patients with Parkinson's, but still needs more research to understand the effects of this therapy, as well as test new protocols, especially for short period. Therefore, this study observed the effects of a short WBV protocol in PD patients, evaluating the effects on balance, gait and QOL.

Arias et al (23) analyzed the effects of WBV on QOL of 21 PD patients in a double -blind study, presence of two groups - group treated with WBV $(\mathrm{n}=10)$ and placebo group ( $\mathrm{n}=11)$, by using a protocol that consisted only in the patient's stay on the vibration platform, separate in a stable and comfortable position feet, and knees slightly bent, following 5 sets of stimulation of 1 minute each, with a rest period of 1 minute between the series in 12 sessions, over 5 weeks in non-consecutive days and with a frequency of $6 \mathrm{~Hz}$. After 12 sessions, it was suggested that the benefits of WBV reported in the literature are due to a placebo response, because it found no difference between groups. In the present study, although no placebo group, there are different use of reliable tests to determine whether there is a change in balance, gait and QOL in patients treated with WBV.

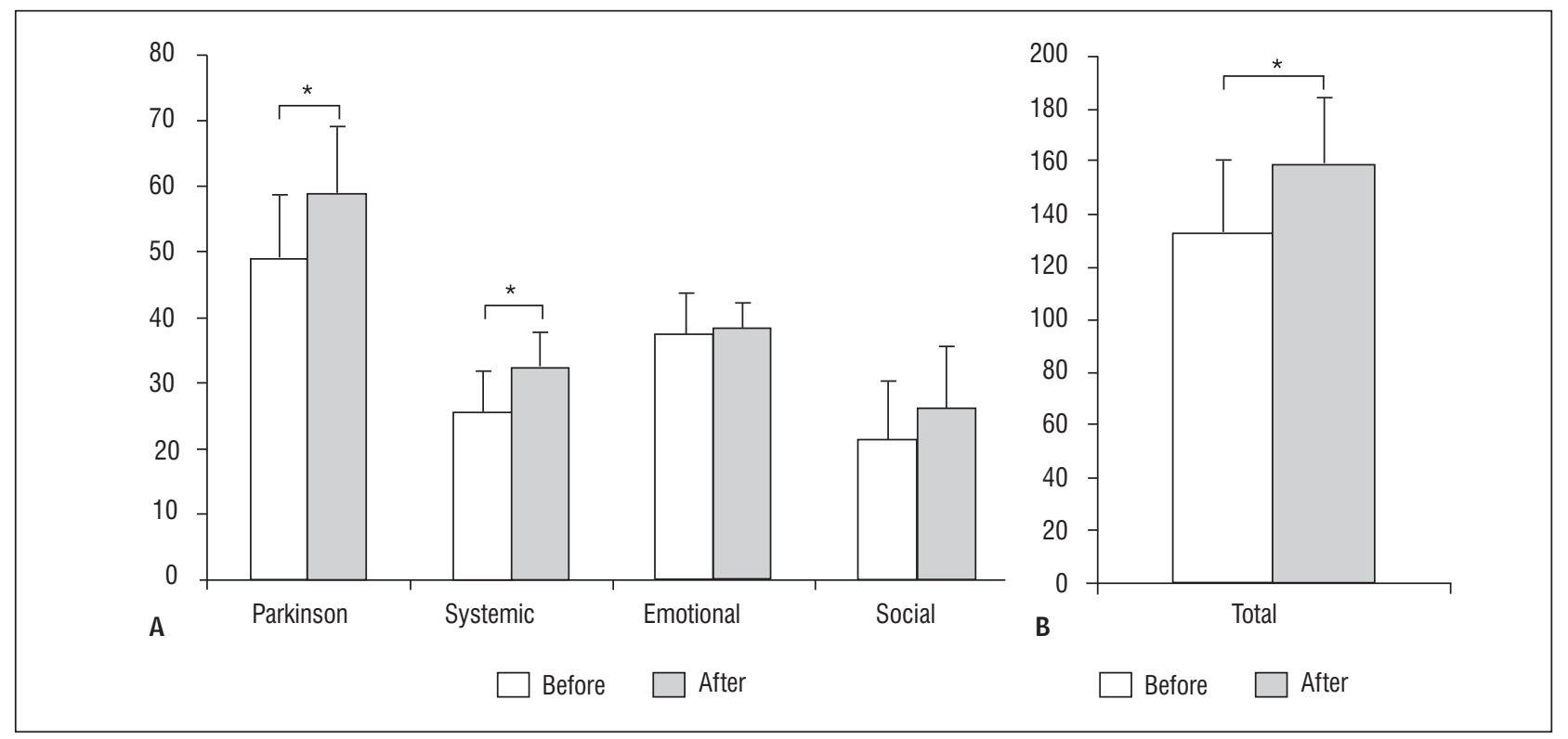

Figure 4 - Parkinson Disease Quality of Life Questionnaire (PDQL-BR): A - Subcategories: Parkinson, Systemic, Emotional and Social, before and after treatment respectively; B - Total Score

Note: ${ }^{\star} \mathrm{p}<0.001$.

Source: Research data.

Fisioter Mov. 2014 abr/jun;27(2):261-70 


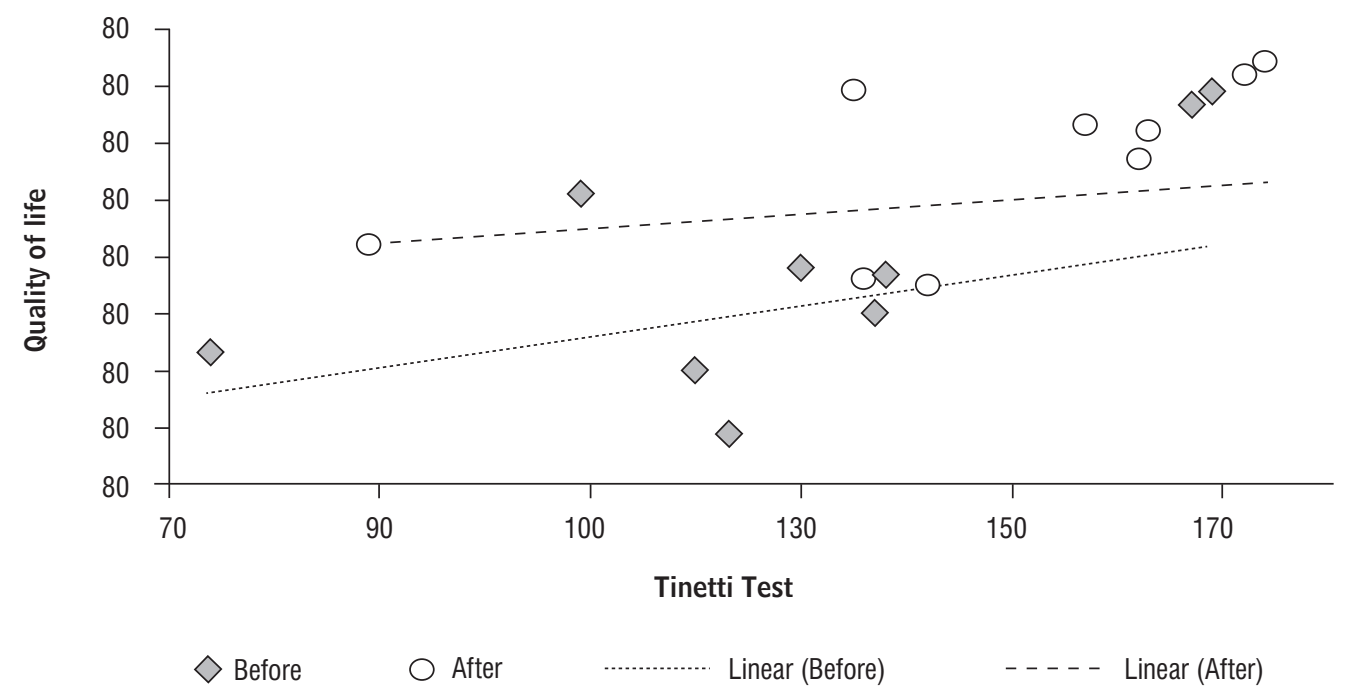

Figure 5 - Correlation between QOL and Tinetti test, before and after whole body vibration treatment Note: $r=0.699, p=0.024$ (before) and $r=0.729, p=0.016$ (after).

Source: Research data.

As a progressive disease, it is expected that WBV decelerate the impairment caused by the disease. Thus, this study followed the deficiency of gait, balance and QOL by comparing test scores before and after treatment. Moreover, the protocol used was more complex, with the completion of four exercises (squats, plantar flexion, isometric contraction of members and single leg balance).

The sample was very specific, characterized by patients who did not respond to drug treatment, different from studies available in the literature, that were referred to physical therapy; thus, it is suggested that improvement in the context of commitment of individuals found in this study were derived only from the treatment in the WBV.

The treatment time on the vibration platform was only 5 minutes in the first 3 sessions and 10 minutes in the remaining 9 sessions. The objective was to test a protocol for short period under the proposed protocol by Foss et al. (22), because previous studies have shown that continued exposure to vibration platform training can cause muscle fatigue (24) and reduce strength of muscle contraction (25), thus compromising the results.

The methodology used in this study to assess the effects of WBV in patients with PD, on balance, gait and QOL is deemed reliable, trustworthy, efficient
(16) and low cost (26). The exercises on the vibration platform were well tolerated by patients. During the implementation of the treatment protocol, blood pressure was monitored and no significant change can cause adverse cardiovascular events or reports of malaise, weakness and muscle fatigue in any of the volunteers. No previous study has reported side effects related to WBV's treatment (27). The Tinetti test (15) has been used in the clinical setting since 1986, and since then, several studies (16) used it as a tool to quantify the changes in balance and gait in PD. In the present study, we noticed a statistically significant improvement in Tinetti Total (11.50 $\pm 7.72 \%)$. This is in agreement with the findings of Bautmans et al. (10) in which the group of seniors who performed WBV exercises had noteworthy changes better than the elderly control group, in the Tinetti test.

This study also assessed the perceived quality of life of individuals with PD through PDQL-BR, once this questionnaire is the one used as the specific instrument being validated in research on QOL for Brazilian individuals with PD (17).

By the development of new treatment methods, as proposed in this study, it is necessary to evaluate the results through instruments that may reflect the factors that influence the QOL of patients. The PDQL-BR allows us to monitor the effectiveness of treatments 
of PD patients by score obtained by conducting a questionnaire of 37 questions relating to Parkinson's symptoms, systemic, social and emotional (17).

In the present study, QOL, according to PDQL-BR, also increased (14.82 $\pm 7.61 \%)$. This suggests better understanding of the individual in relation to their QOL, but it is not possible to predict the stage of PD, by HY scale, may suffer regression by higher scores obtained by PDQL-BR or vice versa, due to its particularities. However, an individual moved from stage 2 to stage 1 in HY.

The results obtained for each sub-category of PDQL-BR revealed significant changes in items referring to symptoms of Parkinson's disease and systemic. Other studies make use of similar instruments to assess QOL in PD, namely, Lana et al. (28) observed higher perceptions of QOL in dimensions "activities of daily living" and "mobility" when used the PDQ-39 questionnaire. Unlike the questionnaire used in this study, the PDQ-39 is a validated U.S. English, which was translated into Brazilian Portuguese. Another study assessed QOL by using the PDQ-39 and found that shortages of motor origin negatively influence on the perception of quality of life (29).

Yousefi et al. (26) compared the effects of 10 weeks of exercise therapy in combination with administration of drugs in 12 patients with PD, in stage 3 in the range of HY with 12 patients who just received the drugs. They concluded that therapeutic exercises were effective in perception of QOL in patients with PD in conjunction with drug therapy. These results confirm the findings of this research, because the improvement in QOL was, on average, almost $15 \%$.

It is noteworthy that the treatment time was used around 3-4 times lower than that used in conventional physical therapy (9). Thus, this short period protocol becomes acceptable to patients as well since it is fast and with satisfactory results.

In the present study, the sample was characterized by equal distribution between men (50\%) and women (50\%), and we pointed out that there was no difference in treatment responses between the sexes. Although Wooten et al. (30) claim that the incidence of PD in males is 1.5 times higher than in women.

The adopted parameters on the vibration platform are according to the proposed studies in the elderly population $(\mathrm{a}=2 \mathrm{~mm}, \mathrm{f}=35 \mathrm{~Hz})(31)$. Thus, these parameters provided greater certainty to people during the course of treatment without interfering with the freedom of movement. Thus, this treatment modality with these parameters is consistent with the model of ideal physical therapy for Parkinson proposed by Morris (3).

In this study, emphasis was placed on the muscles of the lower limbs, based on improvement of muscle strength of the lower limbs with freely and actively exercises on the variation of gravity conditions that can be produced by vibrating platform. It is essential for patients with PD to perform physical exercises. This study is the only one to show the relationship between balance and gait (through the scores of the Tinetti test) with the quality of life (through PDQLBR). Through this, a positive correlation between the score of the Tinetti test with a score of PDQLBR was observed. Such correlation increased after WBV training, suggesting that therapeutic modalities that increase the score of the Tinetti test also induce improvement in QOL of PD patients. This is because the benefits of physical exercise in elderly patients with PD may be obtained by increasing the blood flow to the brain, which carries oxygen and other energy substrates that act in the synthesis and metabolism of neurotransmitters, by the increasing of antioxidant enzymes activity, allowing increased defense capacity against oxidative stress in the central nervous system, with similar stroke in other tissues (32).

\section{Conclusion}

The WBV exercises performed on the vibration platform, according to the parameters used in this study, in patients with PD, showed promising results that support future studies and encourage its use to improve clinical conditions related to disturbances of gait, balance and QOL, according to the results of the Tinetti Test and PDQL-BR.

\section{References}

1. Coppedè F. Genetics and epigenetics of Parkinson's disease. Scientific World J. 2012;2012: ID 489830.

2. Lees AJ, Hardy J, Revesz T. Parkinson's disease. Lancet. 2009;373(9680):2055-66.

3. Morris ME. Movement disorders in people with Parkinson disease: a model for physical therapy. Phys Ther. 2000;80(6):578-97. 
4. Starkstein SE, Bolduc PL, Mayberg HS, Preziosi TJ, Robinson RG. Cognitive impairments and depression in Parkinson's disease: a follow up study. J Neuropsychiatry Clin Neurosci. 1990;53(7):597-602.

5. Quelhas R, Costa M. Anxiety, depression, and quality of life in Parkinson's disease. J Neuropsychiatry Clin Neurosci. 2009;21(4):413-9.

6. Starkstein SE, Preziosi TJ, Bolduc PL, Robinson RG. Depression in Parkinson's disease. J Nerv Ment Dis. 1990;178(1):27-31.

7. Karlsen KH, Tandberg E, Arsland D, Larsen JP. Health related quality of life in Parkinson's disease: a prospective longitudinal study. J Neurol Neurosurg Psychiatry. 2000;69(5):584-9.

8. Behari M, Srivastava AK, Pandey RM. Quality of life in patients with Parkinson's disease. Parkinsonism Relat Disord. 2005;11(4):221-6.

9. Ebersbach G, Edler D, Kaufhold O, Wissel J. Whole body vibration versus conventional physiotherapy to improve balance and gait in Parkinson's disease. Arch Phys Med Rehabil. 2008;89(3):399-403.

10. Bautmans I, Van HE, Lemper JC, Mets T. The feasibility of Whole Body Vibration in institutionalised elderly persons and its influence on muscle performance, balance and mobility: a randomised controlled trial (ISRCTN62535013). BMC Geriatr. 2005;5:17.

11. Rauch F, Sievanen H, Boonen S, Cardinale M, Degens $\mathrm{H}$, Felsenberg D, et al. Reporting whole-body vibration intervention studies: recommendations of the International Society of Musculoskeletal and Neuronal Interactions. J Musculoskelet Neuronal Interact. 2010;10(3):193-8.

12. Rees SS, Murphy AJ, Watsford ML. Effects of wholebody vibration exercise on lower-extremity muscle strength and power in an older population: a randomized clinical trial. Phys Ther. 2008;88(4):462-70.

13. Effects of whole body vibration on postural steadiness in an older population. J Sci Med Sport. 2009;12(4):440-4.

14. Bruyere O, Wuidart MA, Di Palma E, Gourlay M, Ethgen $\mathrm{O}$, Richy F, et al. Controlled whole body vibration to decrease fall risk and improve health-related quality of life of nursing home residents. Arch Phys Med Rehabil. 2005;86(2):303-7.
15. Tinetti ME. P Performance-oriented assessment of mobility problems in elderly patients. J Am Geriatr Soc. 1986;34(2):119-26.

16. Kegelmeyer DA, Kloos AD, Thomas KM, Kostyk SK. Reliability and validity of the Tinetti Mobility Test for individuals with Parkinson disease. Phy Ther. 2007;87(10):1369-78.

17. Campos M, Rezende CHA, Farnese VC, Silva CHM, Morales NMO, Pinto RMC. Translation, Cross-Cultural Adaptation, and Validation of the Parkinson's Disease Quality of Life Questionnaire (PDQL), the "PDQL-BR", into Brazilian Portuguese. ISRN Neurol. 2011;2011:954787.

18. Pinto NS, Monteiro MB, Meyer PF, Santos-Filho SD, Azevedo-Santos F, Bernardo RM, et al. T The effects of whole-body-vibration exercises in Parkinson's disease: a short review. J Med Med Sci. 2010;2(1):594-600.

19. del Pozo-Cruz B, Adsuar JC, Parraca JA, Olivares PR, Herrera E, Gusi N. Whole-body vibration effects in patients affected with Parkinson's disease: a systematic literature review. Rev Andal Med Deporte. 2011;4(2):63-70.

20. Hoehn MM, Yahr MD. Parkinsonism: onset, progression, and mortality. Neurology. 1967;17(5):427-42.

21. Bertolucci PHF, Brucki SMD, Campacci SR, Juliano Y. O Mini-Exame do Estado Mental em uma população geral: impacto da escolaridade. Arq Neuropsiquiatr. 1994;52(1):1-7.

22. Foss ML, Keteyian SJ, Fox EL. Fox's physiological basis for exercise and sport. Boston: WCB/McGrawHill; 1998.

23. Arias P, Chouza M, Vivas J, Cudeiro J. Effect of whole body vibration in Parkinson's disease: a controlled study. Mov Disord. 2009;24(6):891-8.

24. Adamo D, Martin B, Johnson P. Vibration-induced muscle fatigue, a possible contribution to musculoskeletal injury. Eur J Appl Physiol. 2002;88(1-2):134-40.

25. Necking LE, Lundborg G, Fridén J. Hand muscle weakness in long-term vibration exposure. J Hand Surg Br. 2002;27(6):520-5.

26. Yousefi B, Tadibi V, Khoei A, Montazeri A. Exercise therapy, quality of life, and activities of daily living in patients with Parkinson disease: a small scale quasirandomised trial. Trials. 2009;10:67. 
27. de Lau LM, Giesbergen PC, de Rijk MC, Hofman A, Koudstaal PJ, Breteler MM. Incidence of parkinsonism and Parkinson disease in a general population: the Rotterdam Study. Neurology. 2004;63(7):1240-4.

28. Lana RC, Álvares LMRS, Nasciutti-Prudente C, Goulart FRP, Teixeira-Salmela LF, Cardoso FE. Percepção da qualidade de vida de indivíduos com doença de parkinson através do PDQ-39. Rev Bras Fisioter. 2007;11(5):397-402.

29. Silva JAMG; Dibai Filho AV, Faganello FR. Mensuração da qualidade de vida de indivíduos com a doença de Parkinson por meio do questionário PDQ-39. Fisioter Mov. 2011;24(1):141-6.

30. Wooten GF, Currie LJ, Bovbjerg VE, Lee JK, Patrie J. Are men at greater risk for Parkinson's disease than women? J Neurol Neurosurg Psychiatry. 2004;75(4):637-9.
31. Kawanabe K, Kawashima A, Sashimoto I, Takeda T, Sato Y, Iwamoto J. Effect of whole-body vibration exercise and muscle strengthening, balance, and walking exercises on walking ability in the elderly. Keio J Med. 2007;56(1):28-33.

32. Tanaka K, Quadros Junior AC, Santos RF, Stella F, Gobbi LTB, Gobbi S. Benefits of physical exercise on executive functions in older people with Parkinson's disease. Brain Cogn. 2009;69(2):435-41.

Received: 03/28/2013

Recebido: 28/03/2013

Approved: 09/15/2013

Aprovado: 15/09/2013 